\title{
Main characteristics and participation rate of European adolescents included in the HELENA study
}

Laurent Béghin ${ }^{1,2^{*}}$, Inge Huybrechts ${ }^{3}$, German Vicente-Rodríguez ${ }^{4}$, Stefaan De Henauw ${ }^{3}$, Frédéric Gottrand ${ }^{1,2}$, Marcela Gonzales-Gross ${ }^{5}$, Jean Dallongeville ${ }^{6}$, Michael Sjöström ${ }^{7}$, Catherine Leclercq $^{8}$, Sabine Dietrich ${ }^{9}$, Manuel Castillo ${ }^{10}$, Maria Plada ${ }^{11}$, Dénes Molnar ${ }^{12}$, Mathilde Kersting ${ }^{13}$, Chantal C Gilbert ${ }^{14}$ and Luis A Moreno ${ }^{4}$

\begin{abstract}
Background: Participation rate and response rate are key issues in a cross sectional large-scale epidemiological study. The objective of this paper is to describe the study population and to evaluate participation and response rate as well as the key nutritional status variables in male and female adolescents involved in the HELENA study.

Methods: A multi-stage random cluster sampling with a target sample of 3000 adolescents aged [12.5 to 17.5] years, stratified for geographical location and age, was carried out. Information for participants and non-participants (NP) was compared, and participation and response rates to specific questionnaires were discussed.

Results: 3,865 adolescents aged [12.5 to 17.5 ] years (1,845 females) participated in the HELENA study, of whom 1,076 (568 females) participated in the blood sampling. 3,528 (1,845 females) adolescents were finally kept for statistical analysis. Participation rates for the schools and classes differed importantly between countries. The participation rate of pupils within the participating classes also differed importantly between countries. Sex ratio, mean age and BMI were similar between NP and participating adolescents within each centre, and in the overall sample. For all the questionnaires included in the database, the response rate of questionnaires was high (more than $80 \%$ of questions were completed).

Conclusion: From this study it could be concluded that participation rate differed importantly between countries, though no bias could be identified when comparing the key study variables between participants and non-participants. Response rate for questionnaires was very high. Future studies investigating lifestyle and health in adolescents can optimize their methods when considering the opportunities and barriers observed in the HELENA study.
\end{abstract}

\section{Background}

Non-communicable diseases, including obesity, are the most common causes of morbidity and mortality in European adults, and they may originate in childhood and adolescence [1-3]. The complex interaction between genetics, growth and the environment that could be behind these diseases is poorly understood in adolescence. It has been hypothesised that a reduction in the risk factors for non-communicable diseases during growth may reduce morbidity and mortality impact later

\footnotetext{
* Correspondence: laurent.beghin@chru-lille.fr

${ }^{1}$ Inserm U955, IFR 114/IMPRT, Faculty of Medicine, Université Lille Nord de France, F-59037 Lille, France

${ }^{2}$ CIC-PT- 9301-CH\&U-Inserm of Lille, CHRU de Lille, F-59037 Lille, France

Full list of author information is available at the end of the article
}

in life [4]. Major risk factors such as inadequate dietary habits [5-7] and physical inactivity [8-10] have been described. However, due to the complexity of the problem, the solution implies a collaborative and a multidisciplinary strategy to preserve a healthy physiological and psychological development during adolescence.

The first step towards addressing the problem is to acquire a reliable description of the current situation. The "Healthy Lifestyle in Europe by Nutrition in Adolescence" (HELENA) study (http://www.helenastudy.com), is a European cross-sectional study (CSS) supported within the European Commission's $6^{\text {th }}$ Framework Program. The study aimed to obtain a complete picture of the nutritional status, body composition, lipids and metabolic profile,
C Biomed Central

(c) 2012 Béghin et al.; licensee BioMed Central Ltd. This is an Open Access article distributed under the terms of the Creative Commons Attribution License (http://creativecommons.org/licenses/by/2.0), which permits unrestricted use, distribution, and reproduction in any medium, provided the original work is properly cited. 
vitamin status, immune function related to nutritional status, physical activity and fitness levels, food choices and preferences, and genotype (analysing gene-nutrient and gene-environment interactions), by collecting data around 3000 adolescents in 10 European cities using the same methodology [11-13].

The aim of the present paper is to describe the study population and the key nutritional status variables in male and female adolescents involved in the HELENA study and compare basic variables (ie: gender and Body Mass Index) between participating to non-participating adolescents in HELENA study. These analyses were performed in order to check for possible selection bias.

\section{Methods}

Prior to the initiation of the HELENA study, all methods were tested in a pilot study in order to test the sampling procedure, to improve blood transport logistics and analytics, and to optimise all questionnaires and exams [11]. In terms of study design, it was agreed that recruitment at a school setting would combine reliability (for comparisons) and feasibility (from a practical point of view). For practical reasons, and taking into account both educational and psychological considerations, complete school classes from the grades that best corresponded to the selected age group were selected.

\section{Study sample}

The basis for the selection of the European cities was a practical one in the first instance, since it was not realistic to include a random sample of European adolescents given the timeline and budget available in the HELENA project.

\section{Target population and sample size estimation}

The aim of the HELENA study was to obtain a complete picture of the nutritional status, body composition, lipids and metabolic profile, vitamin status from a the target population: European adolescents [12.5-17.5] years old. Variance of BMI was chosen to calculate the sample size because this variable has the greatest dispersion in the study population with regards to the problem under consideration. The sample size was calculated with a confidence level of $95 \%$, with \pm 0.3 error in the parameter BMI. Error of 0.3 was chosen as a worst case scenario as precision level described by Cochran WG [14]. The number of adolescents to be studied was estimated at 3000 (300 in each centre). A subgroup of adolescents from the 10 cities was also randomly selected at class level (cf. Infra) to participate in blood sampling. We planed to analyse 74 blood parameters (excluding genetics) [15]. As 10 subjects per parameter are at least necessary to perform multivariate analysis, we considered than 740 subjects $(74 \times 10)$ were required for blood sampling and in order to prevent drop out, analysis/technical problems, we planned to include a bigger sample of 1000 adolescents.

\section{Selection of the European cities}

It was decided to study a city-based sample, including 10 European cities spread over different geographical areas across Europe striving for representativeness at the level of these cities. The cities were selected by convenience based on the location of the partners in the HELENA study consortium. Each city should have more than 100,000 inhabitants, with various cultural background and socioeconomic situation; presence of an active research group assuring sufficient expertise and resources to successfully perform studies in adolescents and an infrastructure allowing studies on adolescent health. Within the study, Stockholm (Sweden) represented Northern Europe; Athens and Heraklion (Greece), Roma (Italy) and Zaragoza (Spain) Southern Europe; Pécs (Hungary) Eastern Europe; and Ghent (Belgium) and Lille (France) Western Europe, and Dortmund (Germany), Vienna (Austria) Central Europe. In addition, an eleventh city, Birmingham UK, also participated in the HELENA CSS using the same selection and recruitment criteria. However, adolescents in the UK center only engaged in the study on food choices and preferences and therefore this sample has not been included in the descriptive statistics presented in this paper. A complete description of the HELENA study is available elsewhere [12,13]. Ethical issues, respect for good clinical practice and quality control procedures were addressed in a previous paper [16].

\section{Selection of the study sample}

A multi-stage random cluster sampling was carried out. Firstly, within the selected cities, schools were randomised taking into account several cluster stratifications: private/public school, location/area (zone or district), socio-economic level and age strata. The second step included randomisation of classes. In this random cluster sampling process, stratification was done at two levels, first at the level of cities and secondly at the level of school strata (as mentioned above). Within these strata the individuals are being selected in three stages. The first stage yielding schools as primary sampling units (PSU), and the second stage yielding classes as secondary sampling units (SSU). Individual pupils were then selected in the third stage as tertiary and final sampling units (TSU). Data concerning public/private school status, number of adolescents per class, and class level or grade, were provided by local school authorities. This procedure was carried out to ensure diversity of the sample in cultural and socioeconomic aspects.

The random selection of schools and classes was performed centrally (by the Ghent University) for almost all cities (except for Pecs and Athens, where schools were 
locally selected due to local administrative constraints). A list of 10 randomly selected schools was provided for each centre. At the same time, a replacement list including 20 substitute schools was also provided (replacement schools/classes were for the event of a school/class refusing to participate, and were from the same district and same class level/grade). Overall, 10 schools were involved in the survey in each city with the exception of Pecs where eight schools participated. The eligible school classes were then randomly selected from the list of school after stratification for grade. Up to three classes or class groups from two different grades were selected per school, with no more than 60 adolescents per school. In addition, 5 classes were randomly selected from 4-5 different schools for blood sampling. More details about the selection criteria for schools and classes were previously reported [12]:

The inclusion criteria in the study were:

- Male and female subjects aged [12.5-17.5] years old.

- Schooling in one of the participating classes.

- Informed consent form signed by the parents and/or the legal guardian.

- Subject was not participating simultaneously in another similar research.

Each participating centre was asked to include about 150 male and female adolescents per age stratum: [12.5-14], [14-15], [15-16], [16-17.5] years.

\section{Recruitment strategy}

Each research centre used the same procedure and documents (translated in local language; ie: information letter, consent form) for the adolescent recruitment process.

The first step of the recruitment strategy consisted in by a phone contact with the director/principal of the school. After this, a meeting with the director/principal and main/principal teachers of selected classes was organised in order to present aims, study procedure and require their agreement. The second step consisted in a meeting with adolescents from selected classes and their main/principal teacher. During this meeting (duration of 30 minutes to 1 hour), aims, study procedure and tests were explained. Information and consent forms were then distributed and the adolescents were asked to send their written/signed consent form (including signature of adolescent and both parents) within maximum two weeks after the meeting. If more than $80 \%$ of adolescents from a selected class accepted to participate to the study, class was included in the study. If the rate of acceptance was lower than $80 \%$ another class from the same school was randomly selected, then contacted.

\section{Non participation rate}

Adolescents were selected from participating school classes. In order to be as representative as possible of these European cities, schools and classes were randomly selected. This procedure of course implies non-participation (NP) which can introduce substantial error into the results, particularly when the participation rate is very low [17]. Moreover, it is difficult to provide information on the nature of the bias and its impact on the final results [18]. In any case, knowing NP rate is very important because low participation rates threaten the external validity of cross-sectional studies [19]. In this context, each research centre was asked to report the number of non-participating adolescents. Due to the two steps randomisation process, NP adolescents come from both non-participating and participating classes. For non-participating classes, it was impossible to collect any information about adolescents (due to ethical and practical points of view). However for NP from participating classes, at least gender, age, weight, and height were collected. These data were collected anonymously by the field workers using health records from school infirmary/ nurse registries/databases, or via direct interview (phone contact) with the parents of NP adolescents using a specific anonymous abbreviated questionnaire, specially designed for this aim as part of the consent procedure.

This procedure was approved by Ethical committee from each country [16].

\section{Response rate of questionnaires}

Response rates were expressed as \% of questions answered.

\section{Selection of participants for statistical analysis}

Exclusions for statistical analysis were carried out a posteriori, without the knowledge of the affected participants, to avoid feelings of discrimination in the excluded adolescents (since all adolescents from a class participated in the study, it was preferred not to exclude any subjects beforehand to avoid that some adolescents would feel discriminated). This procedure gave a final database of 3,528 adolescents eligible for statistical analysis (see Figure 1).

The exclusion criteria for statistical analysis were:

- Male or female subjects aged $<12.5$ or $\geq 17.5$ years

- Weight and/or height information missing

Having a chronic health problem was no an exclusion criteria.

\section{Methods and instruments used Anthropometry}

The anthropometric methods used within the HELENA study were described by Nagy et al. [20]. Briefly, body 


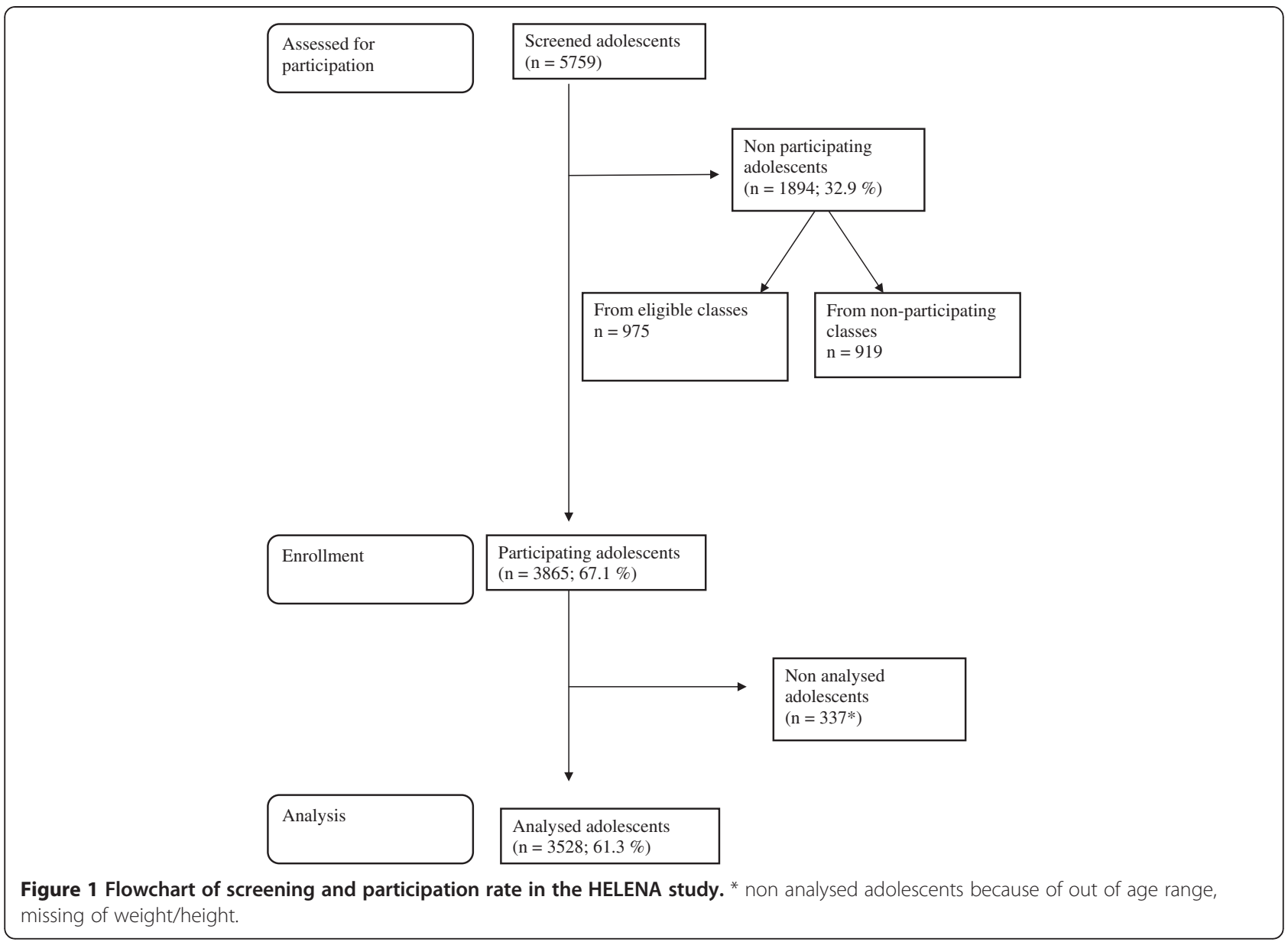

weight was measured in $\mathrm{kg}$ using a standard beam balance (Seca, precision $100 \mathrm{~g}$, range $0-150 \mathrm{~kg}$ ). Height was measured in $\mathrm{cm}$ using a precision stadiometer (Seca, precision $0.2 \mathrm{~cm}$, range $70-200 \mathrm{~cm}$ ). Body mass index (BMI in $\mathrm{kg} / \mathrm{m}^{2}$ ) was calculated as weight $(\mathrm{kg})$ divided by squared height $\left(\mathrm{m}^{2}\right)$. Overweight was defined by means of the international BMI cut-off points for overweight and obesity proposed by The International Obesity Task Force (IOTF); the subjects were divided into overweight and obesity groups, according to the IOTF criteria published by Cole et al. [21]. Subjects with BMI higher than the equivalent 25 and $30 \mathrm{~kg} / \mathrm{m}^{2}$ in adults were described as overweight and obese respectively.

\section{Medical examination, blood sampling and questionnaires}

Medical history, medication used, and all information as described below, were recorded in a specific case report form for each participant. Participants who were selected for the blood sampling were asked to abstain from eating and drinking after 8 p.m the day before the study. On the day of the study, a medical doctor either visited the school classes (in Athens, Dortmund, Ghent, Heraklion, Pecs, Roma, Stockholm, Vienna, Zaragoza), or participants went to a hospital ward (in Lille). Participants were asked for their medical history and recent acute diseases. A blood sampling questionnaire was used to assess fasting status, acute infections, allergies, smoking, vitamin and mineral supplements, and medication. Pubertal status was assessed by means of Tanner stages [22].

Blood pressure was measured with oscillometric devices of the same type and manufacturer (Omron M6) in all the study centres. Subjects sat quietly for 5 minutes, with their back supported, feet on the floor and right arm supported with the cubital fossa at the heart level. Two repeated recordings were made with 5 minutes in between and the lowest value of the 2 recordings of systolic blood pressure (SBP) and diastolic blood pressure (DBP) measurements was recorded.

Blood sampling generally took place between $8-10$ a.m, after blood pressure measurement and body composition assessment by bio-impedancemetry [14]. Approximately $30 \mathrm{~mL}$ of blood was collected from an antecubital vein in serum and heparin monovettes ${ }^{\circledR}$ (Sarstedt AG \& Co., Nümbrecht, Germany). Then, breakfast was offered to all participants. The blood sampling procedure within the HELENA study was described in detail by Gonzalez-Gross 
et al. [15]. Briefly, serum gel tubes were centrifuged at 3,500 rounds per minute (rpm) for 10 minutes within one hour after drawing blood. Within 24 hours serum was transported at room temperature to the central laboratory in Bonn. All samples were stored at $-80^{\circ} \mathrm{C}$ until withdrawn for bunched analyses. Insulin $(\mu l U / m L)$ was analyzed in plasma with IMMULITE $^{\circledR} 2000$ Advanced Immunoassay System (Siemens, Germany). Glucose $(m g / d L)$, total cholesterol (TC; $m g / d L)$, triglycerides $(m g / d L)$, high density lipoprotein cholesterol (HDL; $m g / d L$ ), low density lipoprotein cholesterol (LDL; $m g / d L)$, TC/HDL ratio, LDL/HDL ratio, glutamic oxaloacetic transaminase $(U / L)$ and glutamic pyruvic transaminase $(U / L)$ were analyzed in serum with the RxL clinical chemistry system (Dade Behring, Schwalbach, Germany).

All questionnaires were completed at school during specific time devoted to the study. Two or more fieldworkers were present in the classroom $(i)$ to describe and explain questionnaires (ii) clarify any questions (iii) to assist if needed the adolescent to minimise non response rate.

\section{Statistics}

According to a Shapiro-Wilk test, all variables have normal distribution and are presented as means \pm standard deviation. Prevalence for Tanner stages, overweight + obesity, and obesity, are displayed as percentages. Continuous variables were analysed by two-tailed $t$-test and categorical variables by the Chi-Square test.

A weighing factor for the whole sample, and a specific one for the subsample with blood assessments, was applied in order to adjust the final sample in the analyses to the theoretical distribution for age and gender. The SPSS 15.0 software for Windows (SPSS Inc, Chicago, Illinois) was used for the analyses and the significance level used was $5 \%$.

\section{Results}

\section{Participation rate and final database}

Figure 1 presents a flow chart describing the recruitment process and expressing the participation rate. As whole classes were invited to take part, more subjects were included than was required from the sample size calculations, with a final sample of 3,865 adolescents included in the HELENA-CSS. Finally, 337 adolescents were not analysed because they were out of age range $(n=335)$, or have missing of weight/height $(n=2)$. Table 1 presents an overview of the participation rate of the different sampling units for the whole study and for each centre individually. The final database contains a total of 3,528 (1,845 females) adolescents for statistical analysis. The final sample kept for statistical analysis is presented in Table 2 and shows similar repartition of adolescents among gender and age strata.
The participation rate for the schools and classes differed importantly between countries (with Austria having the lowest participation rate: 57\%, and France the highest: 92\% for schools). The participation rate for pupils within the participating classes also differed importantly between countries (ranging from 61\% for France to 95\% for Hungary). Blood sampling was performed in one third of the adolescents recruited (selection of entire classes representing the desired age of the adolescents); in total, 1,076 adolescents (568 females) participated in the blood sampling. For most countries, the participation rate for the adolescents invited to participate in the blood sample subgroup was similar to the total participation rate in that country (except for Italy where the participation rate was $80 \%$ for the total sample versus $60 \%$ for the adolescents giving blood samples).

\section{Comparison of characteristics between participants and non-participants}

Table 3 presents information related to gender, age, weight, and height collected in NP subjects from participating classes. It was not possible to collect this information in non-participating classes because in this case the class was excluded before any field work started and we were not allowed by school authorities to have any contact with these adolescents or their parents. In some occasions, information about NP subjects from participating classes was also lacking because teachers or school directors did not want to provide any data from these adolescents, to respect the NP's privacy and their decision not to participate. In total we could collect complete information from $710 \mathrm{NP}$ adolescents out of the $975 \mathrm{NP}$ from the participating classes. Sex ratio, mean age and reported BMI were similar between NP and participating adolescents within each centre, and in the overall sample (Table 3 ).

\section{Response rate for questionnaires}

The HELENA study contains 10 different questionnaires addressing a range of topics including perceived health, socio-economic status, and adolescents' knowledge and attitudes towards nutrition and physical activity. Participating adolescents were invited to answer 474 questions in total. Our challenge was to obtain maximum cooperation from the adolescents in terms of understanding the questions, in order to minimize the risk of nonresponse and errors [23]. Table 4 presents the number of questions in each questionnaire, percentage of questionnaires present in the database (whether the questionnaire was totally completed or not by the adolescents), and percentage of answered questions within questionnaires. Percentage of questionnaires present in the database differed according to the type of questionnaire and ranged from $83.6 \%$ for the larger Food Choices and 
Table 1 Number of approached/participating classes and adolescents in the HELENA study \#

\begin{tabular}{|c|c|c|c|c|c|c|c|c|c|c|}
\hline CENTERS & Athens & Dortmund & Ghent & Heraklion & Lille & Pecs & Roma & Stockholm & Vienna & Zaragoza \\
\hline Number of eligible schools in the city & 82 & 55 & 43 & 22 & 40 & 12 & 290 & 25 & 347 & 83 \\
\hline Number of schools approached/participating & $17 / 10$ & $14 / 11$ & $11 / 9$ & $11 / 10$ & $13 / 12$ & $8 / 7$ & $18 / 10$ & $14 / 10$ & $23 / 13$ & $16 / 12$ \\
\hline Number of classes approached/participating & $14 / 14$ & $23 / 23$ & 20/19 & $22 / 20$ & $19 / 18$ & $24 / 14$ & $24 / 22$ & $25 / 23$ & $35 / 19$ & $26 / 23$ \\
\hline $\begin{array}{l}\text { Number of adolescents approached in all } \\
\text { approached classes }\end{array}$ & 458 & 603 & 429 & 429 & 538 & 720 & 470 & 645 & 870 & 597 \\
\hline $\begin{array}{l}\text { Number of adolescents approached in all participating } \\
\text { classes/adolescents participating }\end{array}$ & $458 / 370$ & $603 / 515$ & $413 / 347$ & $400 / 340$ & $508 / 308$ & $420 / 401$ & 430/339 & $535 / 377$ & $536 / 427$ & $537 / 441$ \\
\hline Number of adolescents eligible for statistical analysis & $321(70 \%)^{*}$ & $476(79 \%)^{*}$ & $336(78 \%)^{*}$ & $284(66 \%)^{*}$ & $287(53 \%)^{*}$ & $394(55 \%)^{*}$ & $304(65 \%)^{*}$ & $341(53 \%)^{*}$ & $403(63 \%)^{*}$ & $382(64 \%)^{*}$ \\
\hline \multicolumn{11}{|l|}{ BLOOD SAMPLE } \\
\hline $\begin{array}{l}\text { number of classes approached/participating for } \\
\text { blood sample }\end{array}$ & $6 / 6$ & $8 / 8$ & $6 / 6$ & $8 / 8$ & $8 / 6$ & $5 / 5$ & $10 / 9$ & $8 / 5$ & $10 / 7$ & $7 / 7$ \\
\hline $\begin{array}{l}\text { number of adolescents approached/participating for } \\
\text { blood sample }\end{array}$ & $161 / 137$ & 155/136 & $145 / 125$ & $142 / 122$ & $177 / 108$ & $150 / 141$ & $186 / 112$ & $150 / 128$ & 198/125 & $136 / 125$ \\
\hline Number of adolescents eligible for statistical analysis & $104(65 \%)^{*}$ & $122(79 \%)^{*}$ & $113(78 \%)^{*}$ & $104(85 \%)^{*}$ & $86(49 \%)^{*}$ & $136(91 \%)^{*}$ & $101(55 \%)^{*}$ & $99(66 \%)^{*}$ & $112(56 \%)^{*}$ & $112(82 \%)^{*}$ \\
\hline
\end{tabular}

\# Data collected from 2006 to 2007.

* Percentage calculated to reflect ratio of selected adolescents for statistical analysis to adolescents approached in all approached classes. 
Table 2 Repartition of number of adolescents by gender and age strata in the HELENA study final sample ${ }^{\text {\# }}$

\begin{tabular}{llllll}
\hline Age strata (Years) & \multicolumn{2}{c}{ Females } & & \multicolumn{2}{c}{ Males } \\
\cline { 2 - 3 } \cline { 6 - 7 } & $\mathbf{n}$ & $\mathbf{6}$ & & $\mathbf{n}$ & \% \\
\hline$[12.5-14]$ & $\mathbf{6 1 0}$ & 33.1 & & $\mathbf{5 3 0}$ & 31.5 \\
{$[14-15]$} & $\mathbf{4 6 6}$ & 25.3 & $\mathbf{4 0 9}$ & 24.3 \\
{$[15-16]$} & $\mathbf{4 4 0}$ & 23.8 & $\mathbf{4 1 7}$ & 24.8 \\
{$[16-17.5]$} & $\mathbf{3 2 9}$ & 17.0 & $\mathbf{3 2 7}$ & 19.4 \\
\hline
\end{tabular}

$\$$ adolescents were included in ten cities: Athens in Greece, Dortmund in Germany, Ghent in Belgium, Heraklion in Greece, Lille in France, Pecs in Hungary, Roma in Italy, Stockholm in Sweden, Vienna in Austria and Zaragoza in Spain. "Data collected from 2006 to 2007.

Preferences questionnaire (FCPq), to $97.2 \%$ for both the Nutrition knowledge test (NKT) and the General questionnaire-Socio Economic Status (GQ-SES). More than $83 \%$ of the adolescents agreed to fill in the questionnaires. The relatively high rate of missing Parental Questionnaires (PQ) (about 20\%) is easily explained by the fact that this questionnaire was addressed to the parents who had to send it back to the field worker at the time of the study. For all questionnaires included in the database, the response rate was high, more than $80 \%$. In general, we can consider that once an adolescent decided to respond to a given questionnaire, he/she was generally quite thorough and responded to the majority of the questions.

\section{Migrant status}

The socio-economic questionnaire addressed some questions about origins of adolescents included in HELENA. Migrant adolescents were defined as adolescents born outside the country where they lived. A similar definition was applied for their parents. The proportion (according to total population in HELENA sample) of migrant adolescents (Table 5) varied widely according to each city from 0.6 to $9 \%$ for the adolescents, and from 2.4 to $22.8 \%$ for their parents. Main countries of origin for migrant subjects and their parents were: Turkey, Lebanon, Morocco, Algeria, Serbia, Poland, Ecuador, Slovenia, Romania, Albania, and Russia.

\section{Description of main anthropometric and biochemical variables}

Descriptive data for the study sample is presented in Table 6. Compared to males, females were $8 \mathrm{~cm}$ shorter and $7 \mathrm{~kg}$ lighter, and showed a lower systolic blood pressure (all $\mathrm{p}<0.05$, Table 6). Females were on average in a more advanced stage of sexual maturation and their prevalence of overweight + obesity, and only obesity, were lower than in males (6.9 and 3.5 points of \% respectively; $\mathrm{p}<0.05$, Table 6). Serum concentrations of the main biochemical variables for the study sample are displayed in Table 7 . Compared to males, females exhibited lower glucose, and both glutamic oxaloacetic and glutamic pyruvic transaminases concentrations (all $\mathrm{p}<0.05$, Table 7 ), but higher total cholesterol, triglycerides, and both high and low density lipoprotein cholesterol concentrations (all $\mathrm{p}<0.05$, Table 7).

\section{Discussion}

Sample

In our study the participation rate for the schools and classes differed importantly between countries as was also observed by Klepp et al. [24]. We observed a $67 \%$ mean participation rate for adolescents in our study,

Table 3 Characteristics of the $\mathbf{7 1 0}$ non-participating adolescents from participating classes compared to participating adolescents in HELENA study \#

\begin{tabular}{|c|c|c|c|c|c|c|}
\hline \multirow[t]{2}{*}{ CITIES } & \multicolumn{2}{|c|}{ Sex ratio (M/F) } & \multicolumn{2}{|c|}{ Age (years) (mean $\pm S D)$} & \multicolumn{2}{|c|}{ BMI $\left(k g / m^{2}\right)($ mean $\pm S D)$} \\
\hline & $\begin{array}{c}\text { Non- } \\
\text { participants }\end{array}$ & $\begin{array}{l}\text { Participating } \\
\text { adolescents }\end{array}$ & $\begin{array}{c}\text { Non- } \\
\text { participants }\end{array}$ & $\begin{array}{c}\text { Participating } \\
\text { adolescents }\end{array}$ & $\begin{array}{c}\text { Non- } \\
\text { participants }\end{array}$ & $\begin{array}{l}\text { Participating } \\
\text { adolescents }\end{array}$ \\
\hline Athens & NA & $51 / 49$ & NA & $13.9 \pm 1.2$ & NA & $21.8 \pm 3.8$ \\
\hline Dortmund & $40 / 60$ & $43 / 57$ & $15.0 \pm 1.0$ & $15 \pm 1.4$ & $21.2 \pm 5.2$ & $21.8 \pm 4.2$ \\
\hline Ghent & $49 / 51$ & $54 / 46$ & $15.0 \pm 1.5$ & $15 \pm 1.3$ & $20.9 \pm 3.6$ & $20.3 \pm 3.2$ \\
\hline Heraklion & NA & $54 / 46$ & NA & $14 \pm 1.3$ & NA & $23.2 \pm 4.5$ \\
\hline Lille & $57 / 43$ & $58 / 42$ & $13.8 \pm 1.4$ & $14.4 \pm 1.2$ & $19.5 \pm 6.2$ & $20.5 \pm 3.7$ \\
\hline Pecs & NA & $50 / 50$ & NA & $15 \pm 1.2$ & NA & $21.4 \pm 3.6$ \\
\hline Roma & $40 / 60$ & $60 / 40$ & $15.2 \pm 1.6$ & $15.5 \pm 1.7$ & $21.8 \pm 4$ & $22.2 \pm 4.0$ \\
\hline Stockholm & $47 / 53$ & $61 / 39$ & $14.1 \pm 1.2$ & $15 \pm 1.4$ & $20.9 \pm 3.2$ & $20.5 \pm 3.2$ \\
\hline Vienna & $44 / 66$ & $51 / 49$ & $15.1 \pm 1.4$ & $15.3 \pm 1.5$ & $22.2 \pm 5.1$ & $21.7 \pm 3.7$ \\
\hline Zaragoza & $43 / 57$ & $51 / 49$ & $14.6 \pm 1.2$ & $14.6 \pm 1.3$ & $20.5 \pm 1.9$ & $21.6 \pm 3.3$ \\
\hline TOTAL & $320 / 390$ & $53.3 / 46.7^{\mathrm{NS}}$ & $16.6 \pm 1.2^{* *}$ & $14.8 \pm 1.2^{\mathrm{NS}}$ & $21.1 \pm 4.2^{* *}$ & $21.5 \pm 3.9^{* * N S}$ \\
\hline
\end{tabular}

\# Data collected from 2006 to 2007.

$N A=$ Not Available; NS : Not significant for $t$-test; ${ }^{* *}$ for available data. 
Table 4 Completion and response rates for the HELENA study questionnaires $\$$ \#

\begin{tabular}{lccc}
\hline Questionnaire & $\begin{array}{c}\text { n of } \\
\text { questions }\end{array}$ & $\begin{array}{c}\text { \% of questionnaires } \\
\text { in the database }\end{array}$ & $\begin{array}{c}\text { \% of questions } \\
\text { answered in each } \\
\text { questionnaire } \mathbf{~}^{2}\end{array}$ \\
\hline GQ-SES & 27 & 97.2 & 95.5 \\
NKT & 46 & 97.2 & 98.4 \\
EWI & 60 & 96.4 & 99.6 \\
FCP & 196 & 83.6 & 98.1 \\
HE & 41 & 96.6 & 96.5 \\
PA & 40 & 92.5 & 96.0 \\
PAQ & 22 & 87.5 & 99.9 \\
SQ & 22 & 96.1 & 98.8 \\
PQ & 5 & 80.9 & 98.4 \\
\hline
\end{tabular}

$\$$ adolescents were included in ten cities: Athens in Greece, Dortmund in Germany, Gent in Belgium, Heraklion in Greece, Lille in France, Pecs in Hungaria, Roma in Italy, Stockholm in Sweden, Vienna in Austria and Zaragoza in Spain. " Data collected from 2006 to 2007.

${ }^{1}$ Ratio of number of questionnaires available in the database to the expected number of questionnaires (according to the number of adolescents included).

${ }^{2}$ Ratio of answered questions available in the database to the expected number of questions.

GQ-SES: General questionnaire - Socio economic status questionnaire NKT: Nutrition knowledge test EWI: Eating behavior and weight problems inventory FCP: Food choices and preferences questionnaire HE : Healthy eating determinants PA: Physical activity determinants PAQ: Physical activity questionnaire SQ: Sedentary questionnaire $\mathrm{PQ}$ : Parental questionnaire.

which can be considered acceptable for such a demanding epidemiological study. Indeed, the participation rate in our study was close to those from other comparable epidemiological studies such as the MONICA study: 77.2\% [25] the study of Hill et al.: 75.4\% [26] and 74.7\% [27] obtained in the ProChidren study. Participation rate varied widely among cities, this was probably due to

Table 5 Proportion of migrants by study centre in HELENA study \#

\begin{tabular}{|c|c|c|}
\hline CITIES & $\begin{array}{l}\% \text { of migrant } \\
\text { adolescents }^{\Omega}\end{array}$ & $\begin{array}{c}\% \text { of migrant } \\
\text { parents }^{\Omega}\end{array}$ \\
\hline Athens & 0.6 & 22.8 \\
\hline Dortmund & 5.1 & 15.5 \\
\hline Ghent & 3.6 & 10.1 \\
\hline Heraklion & 1.7 & 2.4 \\
\hline Lille & 3.4 & 11.5 \\
\hline Pécs & 4.0 & 4.7 \\
\hline Roma & 6.3 & 7.6 \\
\hline Stockholm & 9.0 & 11.3 \\
\hline Vienna & 2.0 & 14.5 \\
\hline Zaragoza & 4.8 & 7.9 \\
\hline TOTAL Mean $\pm S D$ & $4.0 \pm 2.4$ & $10.8 \pm 5.8$ \\
\hline
\end{tabular}

\# Data collected from 2006 to 2007.

$\Omega$ Migrant adolescents were defined as adolescents born outside the country where they lived. A similar definition was applied for their parents. (i) time constraints about study procedure perceived differently among cities (ii) different national/local school organisation and (iii) knowledge gap between countries regarding parental perceptions and attitudes toward their children's participation to a research project $[28,29]$. Moreover, the sampling procedure used in the HELENA study contributed to an increase in the nonparticipation rate. This was because classes that had less than $70 \%$ of adolescents who wanted to participate in the study were entirely excluded, thereby excluding individuals in these classes who were willing to participate. Since we were able to collect data from the nonparticipating adolescents from participating classes, we could check whether these subjects had roughly the same characteristics as those who did participate, and therefore whether there were any sampling errors or bias in the selection of HELENA study subjects. Our data show no signs for a significant bias in the participating sample for the key variables in our study (Table 3).

\section{Completion rate and response rate of the questionnaires}

The percentage of missing questionnaires was low in our study and the majority of the questionnaires included in the database had a high rate of completion since most of the questions were answered as was also observed by Klepp et al. [24]. This is a critical point for our study where a large number of self-administered questionnaires were applied, with a risk of weariness and discouragement for the adolescents. In any case, non-responses should not affect data quality when they occur randomly $[18,30]$. Our study is one of the first to report reliability of adolescents for filling out questionnaires. We clearly demonstrated that a good completeness can be obtained in this age group and therefore that results obtained are representative of the total sample of adolescents who participated in the HELENA study.

\section{Clinical and biological characteristics}

Our sample was balanced in terms of repartition and age strata, sex and BMI. To compare BMI between participating and non-participating adolescents, we used weight and height collected from health records from school infirmary registries or self reported data. As weight and height from participating adolescents were measured, this comparison could be biased (direct $v s$ indirect measurement).

SBP and DBP were measured according to methods described in a previous publication [31] Mean SBP and DBP were relatively high compared to data obtained in adolescents studied by Krzyzaniak A et al. [32]. Using cut off values from National High Blood Pressure Education Program Working Group on High Blood Pressure in Children and Adolescents [33] for SBP, we found a unexpectedly high percentage of hypertensive adolescents (i.e. 
Table 6 Descriptive data for female and male adolescents in HELENA study

\begin{tabular}{|c|c|c|c|c|c|c|c|c|c|c|c|c|}
\hline & & Fem & & & & Ma & & & & Tot & & \\
\hline & $\mathbf{n}$ & mean & \pm & SD & $\mathbf{n}$ & mean & \pm & SD & $\mathbf{n}$ & mean & \pm & SD \\
\hline Age $(y r)$ & 1829 & 15.0 & \pm & 1.2 & 1659 & 15.0 & \pm & 1.2 & 3488 & 15.0 & \pm & 1.2 \\
\hline Height $(\mathrm{cm})$ & 1845 & $162.3^{\psi}$ & \pm & 6.8 & 1683 & 170.8 & \pm & 9.4 & 3528 & 166.4 & \pm & 9.1 \\
\hline Weight (kg) & 1845 & $56.4^{\psi}$ & \pm & 10.1 & 1683 & 63.4 & \pm & 14.3 & 3528 & 59.5 & \pm & 12.7 \\
\hline $\mathrm{BMI}\left(\mathrm{kg} / \mathrm{m}^{2}\right)$ & 1845 & 21.4 & \pm & 3.5 & 1683 & 21.6 & \pm & 3.9 & 3528 & 21.5 & \pm & 3.7 \\
\hline Systolic blood pressure $(\mathrm{mm} \mathrm{Hg})$ & 1813 & $117.3^{\psi}$ & \pm & 12.8 & 1631 & 127.1 & \pm & 15.6 & 3444 & 122.0 & \pm & 15.0 \\
\hline Diastolic blood pressure $(\mathrm{mm} \mathrm{Hg})$ & 1813 & 69.2 & \pm & 10.3 & 1631 & 68.7 & \pm & 10.5 & 3444 & 69.0 & \pm & 10.4 \\
\hline Tanner stage $(1 / 2 / 3 / 4 / 5)(n)$ & & $0 / 46^{\Psi} / 308 / 7$ & $4 / 542$ & & & $/ 100 / 310$ & $4 / 46$ & & & & & \\
\hline$\%$ & & $0 / 2.8^{\psi} / 18.8 / 4$ & $\psi / 33$ & & & $6.70 / 20$. & $.5 / 3$ & & & & & \\
\hline Overweight + obesity ${ }^{\Phi}(\%)$ & & 19.5 & & & & 26 & & & & & & \\
\hline Obesity (\%) & & 3.8 & & & & 7. & & & & & & \\
\hline
\end{tabular}

28.15\%; data not shown). As all adolescents included in the HELENA study were presumed healthy, the high percentage of hypertensive adolescents was probably due to methodological bias (white coat effect, stress, few numbers of measures, etc....). This issue should be clarified by undertaking further analysis. As expected, pubertal status was more advanced in girls than boys, which is normal for these age ranges. Ratio of overweight and obese adolescents was within habitual range according to Lobstein T et al. [34]. Serum concentrations for the main biochemical characteristics were also in the normal range $[33,35,36]$. The most striking results in this regard were the higher values in girls for all of the studied lipidrelated variables. These results are in accordance with results observed in Turkish children and adolescents aged 7-18 years [37]. However, Spanish girls had only high total cholesterol and high density lipoprotein cholesterol compared to their male counterparts [38]. Differences between studies may be due to genetic variation and/or different eating behaviors between countries; methodological aspects such as age categorizations and age ranges may contribute to discrepancies. The HELENA study, because of its multi-country design, can minimize these effects.

\section{Conclusion}

The HELENA study offers the opportunity to study the interaction of nutrition and health in a European adolescent population. This study provides, for the first time, a complete picture of their nutrition and health status using high quality data capturing and reporting processes. We clearly demonstrated that a good completeness and a high

Table 7 Serum concentrations for the main biochemical characteristics in female and male adolescents in HELENA study $\$ \#$

\begin{tabular}{|c|c|c|c|c|c|c|c|c|c|c|c|c|}
\hline & & Fem & & & & $\mathrm{Ma}$ & & & & Tot & & \\
\hline & $\mathbf{n}$ & mean & \pm & SD & $\mathrm{n}$ & mean & \pm & SD & $\mathbf{n}$ & mean & \pm & SD \\
\hline Glucose (mg/dL) & 568 & $89.2^{\psi}$ & \pm & 6.8 & 508 & 92.7 & \pm & 7.3 & 1076 & 90.9 & \pm & 7.2 \\
\hline Insulin $(\mu / U / m L)$ & 555 & 10.2 & \pm & 6.4 & 499 & 10.0 & \pm & 8.6 & 1054 & 10.1 & \pm & 7.5 \\
\hline Total cholesterol (TC) (mg/dL) & 568 & $167.1^{\psi}$ & \pm & 27.9 & 508 & 153.4 & \pm & 25.6 & 1076 & 160.6 & \pm & 27.7 \\
\hline Triglycerides (mg/dL) & 568 & $73.5^{\psi}$ & \pm & 37.6 & 508 & 65.0 & \pm & 31.7 & 1076 & 69.5 & \pm & 35.2 \\
\hline High density lipoprotein cholesterol $(m g / d L)$ & 568 & $56.9^{\psi}$ & \pm & 10.9 & 508 & 52.7 & \pm & 9.9 & 1076 & 55.0 & \pm & 10.6 \\
\hline Low density lipoprotein cholesterol (mg/dL) & 568 & $98.0^{\psi}$ & \pm & 25.1 & 508 & 90.4 & \pm & 23.8 & 1076 & 94.4 & \pm & 24.8 \\
\hline TC/HDL ratio & 568 & 3.0 & \pm & 0.6 & 508 & 2.9 & \pm & 0.6 & 1076 & 3.0 & \pm & 0.6 \\
\hline LDL/HDL ratio & 568 & 1.7 & \pm & 0.5 & 508 & 1.7 & \pm & 0.6 & 1076 & 1.7 & \pm & 0.6 \\
\hline Glutamic oxaloacetic transaminase (U/L) & 568 & $20.0^{\psi}$ & \pm & 7.2 & 508 & 24.1 & \pm & 6.8 & 1076 & 21.9 & \pm & 7.3 \\
\hline Glutamic pyruvic transaminase (U/L) & 568 & $19.7^{\psi}$ & \pm & 8.2 & 508 & 23.4 & \pm & 9.2 & 1076 & 21.5 & \pm & 8.9 \\
\hline
\end{tabular}

$\S$ adolescents were included in ten cities: Athens in Greece, Dortmund in Germany, Ghent in Belgium, Heraklion in Greece, Lille in France, Pecs in Hungary, Rome in Italy, Stockholm in Sweden, Vienna in Austria and Zaragoza in Spain. " Data collected from 2006 to 2007.

${ }^{\Psi} \mathrm{P}<0.05$ for comparison between females and males ( $t$-test). 
quality of data can be obtained in this age group. In our study, non-participating adolescents appeared not differ significantly from the participants in the key variables and no sign of selection bias was identified.

Several obstacles, mainly due to the multinational design of the study, were encountered: $(i)$ difference in regulatory requirement among countries [16]; (ii) multilanguage' questionnaires leading to a long process of translation/ crosstranslation [31], (iii) national food composition and habits requiring to adapt software and use national food libraries [39], (iv) harmonisation and accuracy of measurement procedures/tools that needs training and harmonization [20,40], $(v)$ logistics of blood samples through Europe that require precise treaçability [15].

In addition, the practicalities of different aspects included in the study were tested at a pan-European level and were described and discussed in this paper so that future studies dealing with obesity in adolescents and other related factors, can optimize their methods when considering the opportunities and obstacles observed in the HELENA study.

\section{Competing interests}

Frédéric Gottrand has received consulting fees from Numico Clinical Nutrition, lecture fees from SMS and grant support from Danone Research. The remaining authors declare that they have no competing interests.

\section{Authors' contributions}

LAM coordinated the HELENA project on international level. LAM, SD, FG, MGG, JD, MS, CL, MC, DM, MK and CCG were involved in the design of the HELENA project and locally coordinated the HELENA project. LB, GVR, SB, and MP organized the fieldwork and performed the data collection locally. $\mathrm{IH}$ was responsible for the database management. LB was responsible for regulatory issues. $L B, G V R$ and $I H$ drafted the article. All authors read and approved the final manuscript.

\section{Acknowledgement}

The HELENA Study took place with the financial support of the European Community Sitxth RTD Framework Programme (Contract FOOD-CT20056007034). The content of this article reflect only the authors' views and the European Community is not liable for any use that may be made of the information contained therein".

\footnotetext{
Author details

'Inserm U955, IFR 114/IMPRT, Faculty of Medicine, Université Lille Nord de France, F-59037 Lille, France. ${ }^{2}$ CIC-PT- 9301-CH\&U-Inserm of Lille, CHRU de Lille, F-59037 Lille, France. ${ }^{3}$ Department of Public Health, Ghent University, B-9000 Ghent, Belgium. ${ }^{4}$ GENUD (Growth, Exercise, NUtrition and Development) Research Group, Department of Physiotherapy and Nursing, School of Health Sciences, University of Zaragoza, Avd. Domingo Miral $s / n$, E-50009 Zaragoza, Spain. ${ }^{5}$ Department of Health and Human Performance, Faculty of Physical Activity and Sport Sciences (INEF), Universidad Politécnica de Madrid, C/Martín Fierro, 7, E-28040 Madrid, Spain. 'Laboratoire d'épidémiologie et de santé publique, Inserm U744, Institut Pasteur de Lille, Université Lille Nord de France, F-59024 Lille, France. 'Department of Biosciences and Nutrition, Unit for Preventive Nutrition, Karolinska Institutet, Karolinska Institutet, S-10044 Huddinge, Sweden. ${ }^{8}$ Istituto Nazionale di Ricerca per gli Alimenti de la Nutrizione, I-00178 Rome, Italy. ${ }^{9}$ Medical University of Vienna, A-1040 Vienna, Austria. ${ }^{10}$ Department of Medical Physiology School of Medicine, University of Granada, E-18071 Granada, Spain. ${ }^{11}$ Faculty of Medicine, University of Crete, GR-710 03 Heraklion, Greece. ${ }^{12}$ Department of Paediatrics, University of Pecs, H-7624 Pécs, Hungary.

${ }^{13}$ Research Institute of Child Nutrition Dortmund, Rheinische FriedrichWilhelms-Universität Bonn, G-44225 Dortmund, Germany. ${ }^{14}$ Department of
}

Consumer \& Sensory Sciences, Campden BRI, UK-GL1, Gloucestershire, United Kingdom.

Received: 4 October 2011 Accepted: 2 May 2012

Published: 19 June 2012

\section{References}

1. Moreno LA, Sarria A, Fleta J, Rodriguez G, Bueno M: Trends in body mass index and overweight prevalence among children and adolescents in the region of Aragon (Spain) from 1985 to 1995. Int J Obes Relat Metab Disord 2000, 24:925-931.

2. Cook S, Weitzman M, Auinger $P$, Nguyen M, Dietz WH: Prevalence of a metabolic syndrome phenotype in adolescents: findings from the third National Health and Nutrition Examination Survey, 1988-1994. Arch Pediatr Adolesc Med 2003, 157:821-827.

3. Weiss R, Dufour S, Taksali SE, Tamborlane WV, Petersen KF, Bonadonna RC, et al: Prediabetes in obese youth: a syndrome of impaired glucose tolerance, severe insulin resistance, and altered myocellular and abdominal fat partitioning. Lancet 2003, 362:951-957.

4. Franks PW, Hanson RL, Knowler WC, Sievers ML, Bennett PH, Looker HC: Childhood obesity, other cardiovascular risk factors, and premature death. N Engl J Med 2010, 362:485-493.

5. Hu FB, Willett WC: Optimal diets for prevention of coronary heart disease. JAMA 2002, 288:2569-2578.

6. Ding EL, Mozaffarian D: Optimal dietary habits for the prevention of stroke. Semin Neurol 2006, 26:11-23.

7. Gonzalez CA: Nutrition and cancer: the current epidemiological evidence. Br J Nutr 2006, 96(Suppl 1):S42-S45.

8. Fletcher G: Physical inactivity as a risk factor for cardiovascular disease. Am J Med 1999, 107:10S-11S.

9. Kruger HS, Venter CS, Vorster HH: Physical inactivity as a risk factor for cardiovascular disease in communities undergoing rural to urban transition: the THUSA study. Cardiovasc J S Afr 2003, 14:16-23. quiz.

10. Prasad DS, Das BC: Physical inactivity: a cardiovascular risk factor. Indian J Med Sci 2009, 63:33-42.

11. De Henauw S, Gottrand F, De Bourdeauhuij I, Gonzalez-Gross M, Leclercq C, Kafatos A, Molnar D, Marcos A, Castillo M, Dallongeville J, Gilbert C, Bergman P, Widhalm K, Manios Y, Breidenassel LC, Kersting M, Moreno LA on behalf of the HELENA Study Group. Nutritional status and lifestyle of adolescents in a public health perspective. The HELENA Project - Healthy Lifestyle in Europe by Nutrition in AdolescenceJ Public Health2007, 15:187-197.

12. Moreno LA, De Henauw S, Gonzalez-Gross M, Kersting M, Molnar D, Gottrand F, et al: Design and implementation of the Healthy Lifestyle in Europe by Nutrition in Adolescence Cross-Sectional Study. Int I Obes (Lond) 2008, 32(Suppl 5):S4-S11.

13. Moreno LA, Gonzalez-Gross M, Kersting M, Molnar D, De Henauw S, Beghin $L$, et al: Assessing, understanding and modifying nutritional status, eating habits and physical activity in European adolescents: the HELENA (Healthy Lifestyle in Europe by Nutrition in Adolescence) Study. Public Health Nutr 2008, 11:288-299.

14. Cochran WG: In Sampling techniques. 2nd edition. Edited by John Wiley, Sons I. New York: Chapter 11; 1963:134-135.

15. Gonzalez-Gross M, Breidenassel C, Gomez-Martinez S, Ferrari M, Beghin L, Spinneker $A$, et al: Sampling and processing of fresh blood samples within a European multicenter nutritional study: evaluation of biomarker stability during transport and storage. Int J Obes (Lond) 2008, 32(Suppl 5): S66-S75.

16. Beghin L, Castera M, Manios Y, Gilbert CC, Kersting M, De Henauw S, et al: Quality assurance of ethical issues and regulatory aspects relating to good clinical practices in the HELENA Cross-Sectional Study. Int 1 Obes (Lond) 2008, 32(Suppl 5):S12-S18.

17. Lin IF, Schaeffer NC: Using survey participants to estimate the impact of nonparticipation. Public Opinion Quartely 1995, 59:236-258.

18. Groves RM: Nonresponse rates and nonresponse bias in household surveys. Public Opinion Quartely 2006, 70:646-675.

19. Groves RM: The impact of nonresponse rates on nonresponse bias. A meta-analysis. Public Opinion Quartely 2008, 72:167-189.

20. Nagy E, Vicente-Rodriguez G, Manios Y, Beghin L, lliescu C, Censi L, et al: Harmonization process and reliability assessment of anthropometric measurements in a multicenter study in adolescents. Int J Obes (Lond) 2008, 32(Suppl 5):S58-S65. 
21. Cole TJ, Freeman JV, Preece MA: British 1990 growth reference centiles for weight, height, body mass index and head circumference fitted by maximum penalized likelihood. Stat Med 1998, 17(4):407-429.

22. Tanner JM, Whitehouse RH: Clinical longitudinal standards for height, weight, height velocity, weight velocity, and stages of puberty. Arch Dis Child 1976, 51(3):170-179.

23. Olson K: (2006) Survey participation, nonresponse bias, measurement erros bias, and total bias. Public Opinion Quartely 1995, 70:737-758.

24. Klepp Kl, Perez-Rodrigo C, De Bourdeaudhuij I, Due PP, Elmadfa I, Haraldsdottir J, et al: Promoting fruit and vegetable consumption among European schoolchildren: rationale, conceptualization and design of the pro children project. Ann Nutr Metab 2005, 49:212-220.

25. Cottel D, Dallongeville J, Wagner A, Ruidavets JB, Arveiler D, Ferrieres J, et al: The North-East-South gradient of coronary heart disease mortality and case fatality rates in France is consistent with a similar gradient in risk factor clusters. Eur J Epidemiol 2000, 16:317-322.

26. Hill DA, Weiss NS, Beresford SA, Voigt LF, Daling JR, Stanford JL, et al: Continuous combined hormone replacement therapy and risk of endometrial cancer. Am J Obstet Gynecol 2000, 183:1456-1461.

27. Te Velde SJ, Wind M, Perez-Rodrigo C, Klepp Kl, Brug J: Mothers' involvement in a school-based fruit and vegetable promotion intervention is associated with increased fruit and vegetable intakes The Pro Children study. Int J Behav Nutr Phys Act 2008, 5:48.

28. Hayman RM, Taylor BJ, Peart NS, Galland BC, Sayers RM: Participation in research: informed consent, motivation and influence. J Paediatr Child Health 2001, 37:51-54.

29. Nabulsi M, Khalil Y, Makhoul J: Parental attitudes towards and perceptions of their children's participation in clinical research: a developing-country perspective. J Med Ethics 2011, 37:420-423.

30. Langer $\mathrm{G}$ : About response rates, some insolved questions. Public Perspective 2003, 16-18. May/June.

31. Iliescu C, Beghin L, Maes L, De Bourdeaudhuij I, Libersa C, Vereecken C, et al: Socioeconomic questionnaire and clinical assessment in the HELENA Cross-Sectional Study: methodology. Int J Obes (Lond) 2008, 32:S19-S25.

32. Krzyzaniak A, Krzywinska-Wiewiorowska M, Stawinska-Witoszynska B, Kaczmarek M, Krzych L, Kowalska M, et al: Blood pressure references for Polish children and adolescents. Eur J Pediatr 2009, 168:1335-1342.

33. The fourth report on the diagnosis: evaluation, and treatment of high blood pressure in children and adolescents. Pediatrics 2004, 114:555-576.

34. Lobstein T, Frelut ML: Prevalence of overweight among children in Europe. Obes Rev 2003, 4:195-200.

35. Schwimmer JB, Dunn W, Norman GJ, Pardee PE, Middleton MS, Kerkar N, et al: SAFETY study: alanine aminotransferase cutoff values are set too high for reliable detection of pediatric chronic liver disease. Gastroenterology 2010, 138:1357-1364.

36. Jolliffe CJ, Janssen I: Age-specific lipid and lipoprotein thresholds for adolescents. J Cardiovasc Nurs 2008, 23:56-60.

37. Ucar B, Kilic Z, Dinleyici EC, Colak O, Gunes E: Serum lipid profiles including non-high density lipoprotein cholesterol levels in Turkish school-children. Anadolu Kardiyol Derg 2007, 7:415-420.

38. Ruiz JR, Ortega FB, Moreno LA, Warnberg J, Gonzalez-Gross M, Cano MD, et al: Reference values for serum lipids and lipoproteins in Spanish adolescents: the AVENA study. Soz Praventivmed 2006, 51:99-109.

39. Vereecken CA, Covents M, Sichert-Hellert W, Alvira JM, Le DC, De HS, et al: Development and evaluation of a self-administered computerized 24-h dietary recall method for adolescents in Europe. Int J Obes (Lond) 2008, 32:S26-S34.

40. Ortega FB, Artero EG, Ruiz JR, Vicente-Rodriguez G, Bergman P, Hagstromer $M$, et al: Reliability of health-related physical fitness tests in European adolescents. The HELENA Study. Int J Obes (Lond) 2008, 32:S49-S57.

doi:10.1186/0778-7367-70-14

Cite this article as: Béghin et al:: Main characteristics and participation rate of European adolescents included in the HELENA study. Archives of Public Health 2012 70:14.

\section{Submit your next manuscript to BioMed Central and take full advantage of:}

- Convenient online submission

- Thorough peer review

- No space constraints or color figure charges

- Immediate publication on acceptance

- Inclusion in PubMed, CAS, Scopus and Google Scholar

- Research which is freely available for redistribution

Submit your manuscript at www.biomedcentral.com/submit
C Biomed Central 